\title{
Scleroderma in Guinea's African: Epidemiological, Clinical and Therapeutic Aspects
}

\author{
Amadou Kaké1*, Djibril Sylla1, Boh Fanta Diané2, Thierno Amadou Wann1, \\ Alpha Amadou Sank Diallo1, Mohamed Maciré Soumah², Thierno Mamadou Tounkara², \\ Moussa Keita ${ }^{2}$, Mohamed Cissé2
}

\author{
${ }^{1}$ Internal Medicine Department, Donka National Hospital/University Gamal Abdel Nasser of Conakry, Conakry, Guinea \\ ${ }^{2}$ Dermatology Venerology Department, Donka National Hospital/University Gamal Abdel Nasser of Conakry, Conakry, Guinea \\ Email: *amadoukake@gmail.com
}

How to cite this paper: Kaké, A., Sylla, D., Diané, B.F., Wann, T.A., Diallo, A.A.S., Soumah, M.M., Tounkara, T.M., Keita, M. and Cissé, M. (2018) Scleroderma in Guinea's African: Epidemiological, Clinical and Therapeutic Aspects. Open Journal of Internal Medicine, 8, 248-254.

https://doi.org/10.4236/ojim.2018.84023

Received: November 28, 2018

Accepted: December 21, 2018

Published: December 24, 2018

Copyright (c) 2018 by authors and Scientific Research Publishing Inc. This work is licensed under the Creative Commons Attribution International License (CC BY 4.0).

http://creativecommons.org/licenses/by/4.0/

(c) (i) Open Access

\begin{abstract}
Introduction: Scleroderma is a generalized condition of the connective tissue, arterioles and micro-vessels characterized by tissue fibrosis, vascular obliteration and abnormal humoral and cellular immune responses. The aim of this study was to describe the epidemiological, clinical, therapeutic and evolutionary aspects of scleroderma at the Department of Dermatology-Venerology at Donka National Hospital. Methods: This was a descriptive cross-sectional study with a retrospective collection of data for a period of 11 years, from January 1, 2000, to December 31, 2010, covering all inpatient records of Scleroderma in the service. Results: We collected 17 cases of scleroderma out of 3289 , a frequency of $0.04 \%$. The average age of patients was 33.33 years with extremes of 10 and 60 years. A female predominance was noted with a sex ratio $\mathrm{M} / \mathrm{F}$ of 0.13 . Cutaneous induration was the main symptom associated with the phenomenon of Raynaud, and disorders of pigmentation. The extra-skin manifestations were mainly dominated by gastrointestinal involvement (32\%), pulmonary involvement (24\%), cardiac (20\%), articular (20\%) and renal (12\%) involvement. The systemic form was the most common $(99.45 \%)$. Corticotherapy was the most prescribed treatment $(24.59 \%)$. Clinical improvement was noted in $(93.2 \%)$ of the cases. Conclusion: Scleroderma, although rare, deserves special attention at all levels for early diagnosis.
\end{abstract}

\section{Keywords}

Scleroderma, Epidemiology, Clinical, Evolution, Guinea 


\section{Introduction}

Scleroderma (Sc) is a rare autoimmune disease of unknown etiology, characterized by the presence of sclerotic lesions affecting the dermis and/or certain internal organs, associated with vascular changes and immunological abnormalities [1].

Two major forms are described: localized scleroderma and systemic scleroderma whose prognosis is more reserved [2].

Diagnosis can occur in the presence of epidemiological factors' characteristic dermatological lesions and histological data. The cutaneous manifestations have a major interest for the diagnosis, making it possible to evoke it at the first glance. Scleroderma justifies multidisciplinary management combining mainly symptomatic treatments and, in case of visceral involvement, immuno-modulatory treatment [3].

Its exact prevalence is still poorly known with significant disparity between regions and countries. The prevalence is estimated in the United States of America and Australia between 200 and 260 cases/million inhabitants, in Asia between 20 and 50 cases/million inhabitants and in Europe between 100 and 200 cases/million inhabitants [4] [5].

In Africa, data on this condition are patchy. Thus, Tunisia El Fekih and colleagues [6] reported 92 cases of localized scleroderma from 1991 to 2004. Benin Yedomon and his team [7] reported 20 cases of scleroderma between 1980 and 1989. In Senegal 117 cases were reported within 16 years, or 7.3 cases per year [8], while in Burkinas Faso, 14 cases were reported from 1 January 2004 to 31 December 2009 [9].

In Guinea, there are no published data on this condition. The objectives of this study were to determine the hospital prevalence of scleroderma, to describe the socio-demographic and clinical characteristics of patients with Scleroderma, and to assess the modalities of therapeutic and progressive management of patients with scleroderma.

\section{Methods}

This was a descriptive cross-sectional study with a retrospective collection of data from an 11-year period (from January 1, 2000 to December 31, 2010). The study reviewed all the files of patients hospitalized in the Department of Dermatology-Venerology of Donka National Hospital for Scleroderma during the study period.

We included in this study the charts of patients seen for scleroderma diagnosed according to the criteria of the ACR [10], of any age and of any sex, whatever the clinical form, having received a medical treatment and whatever their origin.

We conducted a comprehensive recruitment of all patient records followed for scleroderma. Our data were collected on pre-established survey cards, manually processed, seized; we expressed the quantitative variables on average, and the qualitative variables in percentage. 
The variables of the study were grouped into:

- Sociodemographic variables: Sex, age, occupation and residence.

- Clinical variables: have been sought.

- Functional signs: joint pain, cold sensation, precordialgia, exercise dyspnea, dysphagia, muscular weakness and insomnia.

- Physical signs:

- Mucocutaneous signs: Raynaud's phenomenon, Sclerodactyly, limitation of the perimeter of the mouth, Pigmentation disorder, Cutaneous Xerosis, $\mathrm{Cu}$ taneous atrophy, Sclerosis of the tongue brake, Digitalis pulpal ulcerations, Skin calcifications.

- Extra-cutaneous manifestations: Digestive, Cardiac, Pulmonary, Renal and Joint involvement characteristics.

- Type of scleroderma: localized scleroderma in which cutaneous induration is limited to the distal, limb and facial extremities and systemic sclerosis when induration is associated with the involvement of certain internal organs.

- Topography of the lesions: we considered the following locations: face, neck, trunk, limbs.

- Therapeutic variables: concern the set of treatments received during hospitalization (corticosteroids, antibiotics, immunosuppressants, antihypertensives, nonsteroidal anti-inflammatory drugs, diet and lifestyle measures, and others).

For confidentiality measures we have assigned an identifier to each patient record to preserve anonymity.

The immunological assessment with the antinuclear antibody test was not carried out due to inavailability of resources. So the diagnosis was based solely on clinical evaluation.

The data collected were entered and analyzed in Epi info software version 6.

\section{Results}

Over a period of 11 years (from January 1, 2000 to December 31, 2010), we collected data on 17 cases of scleroderma out of a total of 3289 inpatients. This gives a disease prevalence of $0.04 \%$. The average age of patients was 33.33 years with extremes of 10 and 59 years. The age group 30 - 39 was the most common (47\%), followed by the age group $50-59$ (24\%), the age groups $20-29$ and $40-$ 49 represented $12 \%$ each and age $10-19$ years was $5 \%$. A female predominance was noted, 15 women against 2 men, a sex ratio of 0.13 .

According to socio-occupational categories, housewives were the most frequent (65\%), followed by shopkeepers (12\%) and pharmacists, students, farmers and mechanics, who each accounted for $5.75 \%$. Sixty-seven percent $(67 \%)$ of patients resided in Conakry and 33\% came from within the country.

According to cutaneomucous signs (Table 1), all patients had cutaneous induration. Raynaud's phenomenon and limitation of the oral perimeter were 
Table 1. Distribution of 17 patients with scleroderma according to mucocutaneous signs.

\begin{tabular}{ccc}
\hline Mucocutaneous signs & Number & Percentage (\%) \\
\hline Cutaneous atrophy & 2 & 5.5 \\
Sclerosis of the tongue brake & 1 & 2.7 \\
Edema & 3 & 8.3 \\
Pigmentation disorder & 5 & 13.8 \\
Sclerodactyly & 4 & 11.1 \\
Raynaud's syndrome & 6 & 35 \\
Skin induration & 15 & 100 \\
limitation of the oral perimeter & 6 & 35 \\
Cutaneous xerosis & 2 & 5.5 \\
\hline
\end{tabular}

noted in $35 \%$ of the patients respectively and a disorder of the pigmentation was noted in $29 \%$ of the cases.

The extra-skin manifestations were dominated mainly by gastrointestinal involvement (32\%); followed by pulmonary involvement (24\%), joint involvement and cardiac involvement (20\% respectively) and renal involvement (12\%).

According to the topography of the lesion, the trunk was the most affected (34\%), followed by the face (19\%), limbs (16\%) and neck (13\%). The lesions were generalized in $19 \%$ of cases. The systemic form of scleroderma was the most common (76\%) and the localized form involved $24 \%$ of patients.

All of the patients were put on steroids and hygiene and dietary measures. NSAIDs were prescribed in $87 \%$ of cases and antihypertensive treatment in $40 \%$. One patient (1.6\%) was put on immunosuppressive therapy. Clinical improvement was noted in $94.12 \%$ and death in $5.88 \%$ of cases.

\section{Discussion}

We recorded over 11 years (from January 1, 2000 to December 31, 2010), all cases of scleroderma observed in the service. The retrospective nature of the data collection, the small size of our sample, and the absence of the immunoassay (antinuclear antibodies assay) were the limits of this study. Nevertheless the results allow appreciating the epidemiological, clinical, therapeutic and evolutionary aspects of scleroderma at the service of Dermatology-Venereology of Donka National Hospital. With 17 cases collected in 11 years, our study confirms the rarity of scleroderma as reported in the literature. Indeed, most literature agrees on the low prevalence of this autoimmune disease, notably: in Benin, where Yedomon HG et al. [7] reported 20 cases of scleroderma over a period of 9 years (1980-1989). Ouedraogo DD et al. in Burkina Faso reported 14 cases from 1 January 2004 to 31 December 2009 [9].

The demographic characteristics of our patients are comparable to those found in the literature. These are young adults (mean age $=33.33$ years) and, for the majority, female (88.24\%); as reported by El Fekih $\mathrm{N}$ et al. [6] in Tunisia 
where the average age was 32.33 years with a female predominance of $79.34 \%$; as well as by Yedomon HG et al. [7] in Benin where the average age was 33 years and all patients were female.

This female predominance reinforces the hypothesis of fetal-maternal micro-chemistry in the pathogenesis of scleroderma. Indeed, Lee et al. [11] showed that women with systemic scleroderma had a significantly higher level of $\mathrm{Y}$ chromosome-derived deoxyribonucleic acid (DNA) in their mononuclear blood cells than women who were free of the disease. In addition, these scleroderma women most often had an HLA type II phenotype allowing better tolerance of fetal cells and greater microchemistry. The team of Artlett $\mathrm{N}$ et al. confirmed these results and also found this significant increase at the cutaneous level compared to the control group [12].

However, this theory, although attractive, does not explain the occurrence of systemic scleroderma in children, men or nulliparous women, except, possibly, in case of a history of blood transfusion, organ transplantation, miscarriage or maternofetal passage of maternal cells (maternal anti-fetal reaction), situations that may lead to cellular micro-chemistry.

The clinical manifestations of scleroderma are polymorphic. The sensation of cold found in 7 (14.29\%) of our patients was reported by Hachulla E et al. [13]. Depending on the type of scleroderma, the predominance of the systemic form (11/15 cases) was noted in our series, while in Benin, Yedomon HG et al. [7] reported a predominance of localized forms or 16 cases of localized scleroderma for 4 cases of systemic scleroderma. It is the same for El Fekih et al. [6] in Tunisia, which in 14 years have reported 92 cases of localized scleroderma.

The cutaneous signs noted in our study have been described by other African series, notably that of Yedomon HG et al. in Benin [8]. Indeed, all these studies agree on the frequency of diffuse cutaneous involvement with induration type, speckled achromia (vitiligo spots), the relative rarity and the discretion of Raynaud's phenomenon. These semiological characteristics have already been noted in African black [14]; but in the absence of true epidemiological studies, the individualization of an African form of Scleroderma cannot yet be considered [8]. In Western series, however, the phenomenon of Raynaud is widely described in patients with scleroderma, as reported by Sprynger $\mathrm{M}$ et al. at the University Hospital of Liège [15] who found $90 \%$ of cases of Raynaud's phenomenon in their patients. This is explained by the climatic factors on the one hand, and the diagnostic difficulty of this phenomenon in a black-skinned subject, on the other hand.

The presence of Raynaud's phenomenon would testify to the generalization and progression of the vascular component of Scleroderma.

In addition to the cutaneous manifestations, scleroderma has extra-cutaneous attacks which are frequent and which alter the functional prognosis and may be life-threatening. In our study, the extra-cutaneous lesions were dominated by digestive (32\%), pulmonary (24\%), cardiac and articular (20\%) and renal (12\%) 
lesions. Digestive involvement, as reported in our study, is the most common visceral location of the disease. It can affect all segments of the digestive tract, but that of the esophagus is the most common and best studied; it is found in 50 to $90 \%$ of cases according to the diagnostic method used. The pulmonary involvement is also frequent during scleroderma, it is more severe in diffuse cutaneous forms; pulmonary fibrosis is the most common anatomical expression. It has also been reported by other African series including that of Yedomon HG et al. [8] (1cas). As for cardiac involvement, it is often the consequence of renal or pulmonary complications, however there is a primitive form of extremely common myocardial damage when evaluated by sensitive techniques which, when it leads to clinical signs is very pejorative for the prognosis. In the end kidney damage is the main cause of death specifically scleroderma, and the renal crisis which is manifested by malignant hypertension and acute renal failure, is the main manifestation.

Therapeutically, corticosteroids and lifestyle and dietary measures were used in all patients. Immunosuppressants were used in one patient. In the series of A. Diop et al. [8] In Senegal, corticosteroids were associated with D-penicillamine, hydroxychloroquine or cyclophosphamide in all cases. The inaccessibility of our patients to these treatments of references mentioned above would be explained by their high cost, out of reach of the patients often deprived and living in an extreme precariousness.

On the evolutionary level, in our study, the majority of patients $(94.12 \%)$ evolved favorably. However, we recorded one death case. However, this result should not obscure the severity of scleroderma, especially in its systemic form.

\section{Conclusion}

Scleroderma, although rare, can be localized or systemic and deserves special attention at all levels to obtain early diagnosis and multidisciplinary care.

\section{Conflicts of Interest}

The authors declare no conflicts of interest regarding the publication of this paper.

\section{References}

[1] Bonafe, J., Cambon, L. and Determe, I. (1996) What Is Your Diagnosis: Localized Scleroderma? Dermatological News, 15, 85-86.

[2] Saurat, J.-H., Lachapelle, J.-M., Lipsker, D., Thomas, L. and Borradori, L. (2009) Dermatology and Sexually Transmitted Infection. 5th Edition, Elsevier Masson, Paris, 1152.

[3] Magnant, J. and Doit, E. (2006) Systemic Scleroderma: Epidemiology and Environmental Factors. La Presse Médicale, 35, 1894-1901. https://doi.org/10.1016/S0755-4982(06)74923-5

[4] Roberts-Thomson, P.J. and Walker, J.G. (2006) Scleroderma: It Has Been a Long Hard Journey. Internal Medicine Journal, 36, 519-523. 
https://doi.org/10.1111/j.1445-5994.2006.01138.x

[5] Tamaki, T., Mori, S. and Takehara, K. (1991) Epidemiological Study of Patients with Systemic Sclerosis in Tokyo. Archives of Dermatological Research, 283, 366-371. https://doi.org/10.1007/BF00371817

[6] El Fekih, N., Rejaibi, I., Kamoun, H., Faten, Z., Fazaa, B., Kharfi, M., et al. (2009) Localized Scleroderma: A Retrospective Study of 92 Cases. Medical Tunisia, 87, 573-578.

[7] Yedomon, H.G. and Do-Ango-Padonou, F. (1991) Scleroderma Epidemiologic Study of 20 Cases. Medicine of Black Africa, 38, 491-496.

[8] Diop, A., et al. (2014) Systemic Scleroderma on Black Skin: A Series of 117 Cases. Annals of Dermatology and Venereology, 141, S470. https://doi.org/10.1016/j.annder.2014.09.539

[9] Ouédraogo, D.D., et al. (2014) Connectivities in Hospital Practice in Ouagadougou (Burkina Faso). Tropical Medicine and Health, 24, 271-274.

[10] Tamby, M.C., Chanseaud, Y., Guillevin, L. and Mouthon, L. (2003) New Insights into Pathogenesis of Systemic Sclerosis. Autoimmunity Reviews, 2, 152-157. https://doi.org/10.1016/S1568-9972(03)00004-1

[11] Lee, N., Furst, D.E., Maloney, S., Gooley, T., Evans, P.C., Smith, A., et al. (1997) Microchimerism and HLA-Compatible Relationships of Pregnancy in Scleroderma. Lancet, 351, 559-562.

[12] Artlett, C.M., Smith, J.B. and Jimenez, S.A. (1998) Identification of Fetal DNA and Cells in Skins Lesions from Women with Systemic Sclerosis. New England Journal of Medicine, 338, 1186-1191. https://doi.org/10.1056/NEJM199804233381704

[13] Hachulla, M., et al. (2004) Systemic Scleroderma: Clinical Polymorphism and Therapeutic Aspects. Therapeutic Medicine, 25, 316-325.

[14] Missounga, L. (2017) Mixed Connectivity: Prevalence and Clinical Features in African Black, A Case Study in Gabon and a Review of the Literature. Pan African Medical Journal, 27, 162.

[15] Sprynger, M. (2004) The Phenomenon of Raynaud. Medical Review of Liège, 52, 378-384. 